\title{
A Report on the Meeting ; 2001 ECS/ISE
}

\section{Farid HARRAZ (Kyoto University)}

I have attended with my supervisor the 2001 Joint International Meeting combines the $200^{\text {th }}$ Meeting of The Electrochemical Society (ECS) and the $52^{\text {nd }}$ Annual Meeting of the International Society of Electrochemistry (ISE)-San Francisco, California, USA, September 2-7, 2001. The meeting was held at the San Francisco Hilton \& Tower. It is located in the heart of the theater district, very close to Union Square.

I used Korean Airline. The flight was through Seoul. It took totally about 13 hours from Kansai Airport to arrive San Francisco.

This major international conference is one of the biggest and most important conferences that offers a unique blend of electrochemical and solid-state science and technology. There were 27 topical symposia consisting of 1,575 technical papers scheduled for presentation at this meeting.

My research topic of interest is metal deposition on semiconductor. I have attended many presentations in different sessions that directly touch my interest such as; electrochemical deposition and dissolution, semiconductor and photo-electrochemistry, semiconductor wafer bonding, cleaning technology in semiconductor device manufacturing, and thin film materials, processing and reliability.

In addition to the above symposia I was very interested in the Sixth International Symposium on Quantum Confinement that included some very recent talks about Electrochemistry of Nanostructures, Nanoscale Electronic Devices and Porous Silicon and Silicon Nanocrystals.

Concerning my presentation it was entitled "Metal Deposition onto a Porous Silicon Layer by Immersion Plating from Aqueous and Nonaqueous Solutions". It was scheduled at semiconductor and photo-electrochemistry session.

A group of scientists and specialists from different countries over all the world has attended this meeting. It was really very international. I had the pleasure to meet with my Egyptian supervisor and some of my Cairo University colleagues there after about 2 years from leaving my country. In addition, I made new friends with similar research interest and almost equal age. They are belonging to the research groups of Prof. Schmuki from University of Erlangen, Germany and Prof. Osaka, Waseda University, Japan. I also had a good chance to meet with Prof. Nayfeh, University of Illinois at Urban-Champaign and Dr. Cheng from Xiamen University, see the attached photo.

Indeed, such a meeting provides individuals with an opportunity and a forum to exchange information on the latest scientific and technical developments in their different interesting fields. It was very valuable and interesting for me.

At the end, I'd like to express my deep thanks and sincere appreciation to the Electrochemical Society of Japan for providing me this good opportunity and supporting me financially to attend this meeting.

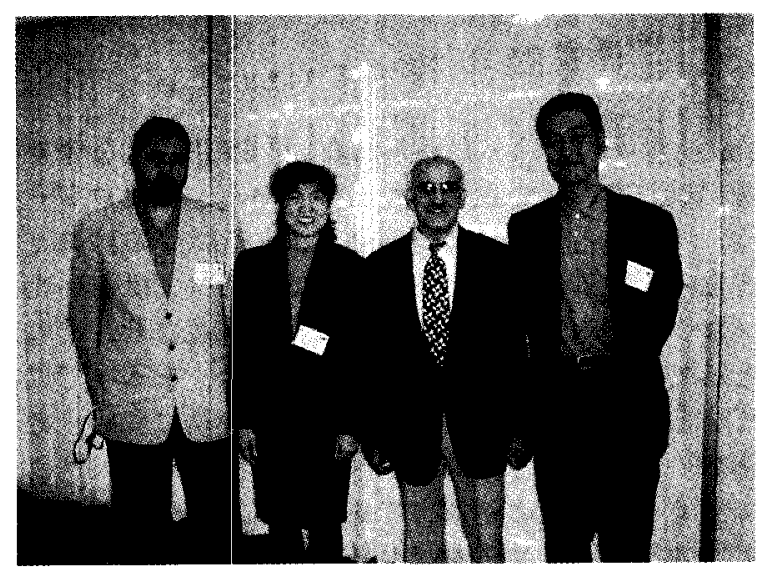

From right, my supervisor Prof. Dr. Y. H. Ogata, Prof. Dr. Munir Nayfeh (USA), Dr. Xuan Cheng (China), and me; Farid Harraz. 